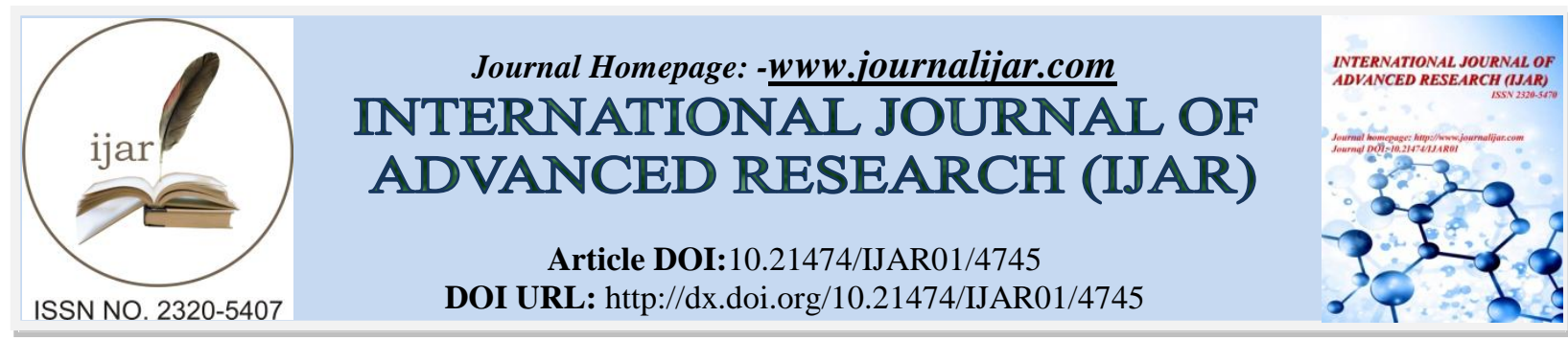

RESEARCH ARTICLE

\title{
CYTOCHROME B AND BETA-FIBRINOGEN IMPLICATION IN THE GENETIC EVOLUTION OF BREAST MALIGNANT TUMOUR IN SENEGALESE WOMEN.
}

\begin{abstract}
Ahmed Mohamed Mze ${ }^{1}$, Fatimata Mbaye ${ }^{1}$, Binta Keneme ${ }^{1}$ and Mbacke Sembene ${ }^{1,2}$.
1. Departement de Biologie Animale, Faculte des Sciences et Techniques, Université C.A. Diop, B.P. 5005 Dakar, Senegal.

2. Centre de Biologie des Populations AnimalesSahéloSoudaniennes (BIOPASS), UMR 022, Institut de Recherche pour le développement, IRD/Bel-Air, Senegal.
\end{abstract}

\section{Manuscript Info}

Manuscript History

Received: 5 May 2017

Final Accepted: 7 June 2017

Published: July 2017

Key words:-

cancer, breast, mutation, DNAmt, Senegal.

\begin{abstract}
The International Cancer Centre (CIRC) stated that there is an important increase of breast cancer throughout the world. In Senegal, breast cancer is known as the malicious tumour more developed among women. From thirty (30) Senegalese women were tested, the notice is that a mitochondrial (Cytochrome b) and a nuclear (Beta-fibrinogen) gene evaluated the level of genetic diversity, genetic differentiation and demographic evolution. Our results showed a real diversity of Cytochrome b compared to Beta-fibrinogen. A significant difference has been found between normal tissues and cancerous ones within Cytochrome b. these results showed an implication of mitochondrial DNA compared to nuclear DNA.
\end{abstract}

Copy Right, IJAR, 2017,. All rights reserved.

\section{Introduction:-}

Cancer is a sickness characterized by the proliferation of an abnormal cell within a normal tissue of a body. These cells come from all from a same clone, the initiator cell of cancer that has acquired some characteristics that permit it to divide itself and to be able to form metastases (Bertram, 2001). There are two types of tumour: benign tumour and malignant ones. In the first case, the tumour is drowned into conjunctive tissue. This encapsulation permits the considerable slowdown of neoplasm's growth, making them less dangerous. Beauty spots and warts are examples of this type of tumour easily eliminable by surgical intervention. In the second case, malignant tumours include no capsulated neoplasm. Tumour mass can, then, increase limitlessly what facilitates its infiltration into tissues as well as its invasion by other organs. Contrary to benign tumours, malignant tumours can kill (Voet, 2002). The International Research Cancer Centre (CIRC) valued the new cases of cancer to 14, 1 thousand (CIRC, 2013). It notices an increase of breast cancer throughout the world and with 1,7 thousand of women diagnosed every year. These last years, incidence and mortality have increased respectively of $20 \%$ and $14 \%$ in the world (OMS, 2013). Breast cancer is the most frequent cause of women death by cancer and the most frequent cancer diagnosed among women in the world. It still be the most serious public health problem, particularly among women of less under 35 year's old where it is aggressive (Axelrod et al., 2008). In Senegal, breast cancer is the second from all the feminine cancers (Dem et al., 2008). Only 5 to 10\% of cancers are hereditary ones (Claus et Risch, 1991) attributable, in majority, to BRCA1 and BRCA2 (DumitrescuetCotarla, 2005). Mitochondria have been suspected for a long time as playing an important role in the development and the progression of cancers. Many associated mitochondrial alteration have been identified and described in literature. These alterations include modification of mitochondrial genes, structural or quantitative mitochondrial abnormalities, or abnormalities of enzymatic components of 
respiratory chain (Wilkieet al., 1983) and currently thanks to technological development of molecular biology, ADNmt mutations.

It was in this framework that we proposed to study $C y t b$ and $F G B$ genetic diversity in malignant breast cancer amongSenegalese women.

\section{Material and Methods:- \\ Samples:-}

The tissues samples used for this study is obtained but surgery of patients affected by breast cancer. In each patient, normal tissues and cancerous tissues were sampled from Aristide Le Dantec Hospital.

\section{Genetic Study:-}

DNAExtraction, Polymerase chain reaction and Sequencing of $C y t b$ and $F G B$ :-

DNA was extracted from patients normal tissues and cancerous tissues using DNA tissue Kit (Qiagen). Cytband $F G B$ were amplified.The amplification has been realized in a reactive volume of $50 \mu 1$ containing $28.9 \mu \mathrm{l}$ of Milliq water, $5 \mu \mathrm{l}$ of buffer (10X)that contain $\mathrm{Mg}^{2+}$ ions to an initial concentration of $15 \mathrm{mM}, 2 \mu \mathrm{l}$ of dNTP,Cytbwas amplified using: H15915 (TCT-CCA-TTT-CTG-GTT-TAC-AAG-AC) and L14723 (ACC-AAT-GAC-ATG-AAA-AATCAT-GGT-T) primers as for $F G B$ : F1 (ATT-CAC-AAC-GGC-ATG-TTC-TTC-AG) and F2 (AAN-GCK-CACCCC-AGT-ATC-TG). PCR happened in a thermocycler of Eppendorfin the following conditions: For Cyt $b$ : preliminary distortion to $94^{\circ} \mathrm{C}$ ( 3 minutes) followed by a repetition of 40 cycles of initial distortion to $92^{\circ} \mathrm{C}$ (45 seconds), hybridization to $50^{\circ} \mathrm{C}$ (1 minute) and complementary DNA strands elongation to $72^{\circ} \mathrm{C}$ during 1 minute 30 seconds and closed by a final elongation (10 minutes) and for $F G B$ : preliminary distortion to $94^{\circ} \mathrm{C}$ ( 3 minutes) followed by a repetition of 40 cycles of initial distortion to $94^{\circ} \mathrm{C}\left(30\right.$ seconds), hybridization to $67^{\circ} \mathrm{C}(1$ minute) and complementary DNA strands elongation to $72^{\circ} \mathrm{C}$ during 1 minute 30 seconds and is closed by a final elongation (10minutes). An electrophoretic migration 1.5\% agarose gel was performed to confine the amplification.Sequencing reactions were performed in a thermolcycle MJ Reseceed PTC 225 pettree type with ABI PRISM Big Dye TM terminatos cycle Kit. Each samples was sequenced using the for word primer for each gene (Cytb, FGB).

\section{Molecular Analysis:- \\ Alignment of $C y t b$ and $F G B$ sequences:-}

$C y t b$ and $F G B$ sequences, of normal and cancerous tissues, are carefully verified, corrected and aligned with BioEdit version 7.0.8 (Hall, 1999) software. The alignment is, in fact an important step of data's analysis. It is also used to bring to light similarities between sequences in finding the position of deletions or of possible insertions.

\section{$C y t b$ and $F G B$ genetic diversity:-}

In order to study the genetic diversity of cancerous tissues in the level of each gene, we determined the number of variable and invariable sites, the number of informative sites, the total number of mutations, the number of haplotypes, the average number of various nucleotides, haplotypical (h) and nucleotide ( $\pi$ ) diversityusing to DnaSP 5.10 (LibradoetRozas, 2009) software. Nucleotide frequencies, the nature of mutations (\% of transitions and tranversions) and molecular distances with Kimura 2 parameter (K2P) model were executed in MEGA version 6.00 (Tamura et al., 2013). Nucleotide frequencies and molecular distances were only calculated for $C y t b$ which is a coding gene in various positions of the codon.

\section{Study of $C y t b$ amino acids variability:-}

$C y t b$ nucleotides sequences are transformed into amino acids sequences using to MEGA software version 6.065 (Tamura et al., 2013)with the best reading frame. The frequencies of amino acids were stand out for normal and cancerous tissue. Chi2 test was realized to see the amino acids that presented significant differences.

$C y t b$ and $F G B$ genetic structure:-

Genetic distances between sane and cancerous tissues at intra and inter individual level for the two genes were explained by the genetic distance of Nei $(\mathrm{Nei}, 1978)$ using MEGAsoftware version 6.06 version software (Tamura $e t$ al., 2013).

\section{Signature selection test:-}

We have made demo-genetic tests that compare the level of adjustment between the two genes diversity and theoretical expected values under the hypothesis of the evolution under a neutralist model (to mutation-derive 
balance). We have, among these tests Tajima D (Tajima, 1989), Fs of Fu (Fu, 1997) and R2 of Ramos (Ramos, 2002). These three tests were realized on FGB. These various estimators are obtained usingDnaSPversion 5.10 (LibradoetRozas, 2009) and Arlequin version 3.5.1.3 (Excoffieret al., 2010). As for Cyt b, the existence of any selection was apprehended by report dN/dS thanks to MEGA 6 softwarewith using Kimura model. dN is the substitution rate not synonymous and dS the substitution rate synonymous. The level of significance was held to $5 \%$ and a bootstrap value of 1000 replications. The distribution disparityanalysis (Mismatch Distribution) that is the graphic representation of distances genetic distribution existing between individuals was also determined. Mismatch analysis is accompanied by two indices that test the quality of distribution adjustment. These indices are SSD (sqarred sums of deviation) and Rag (irregularity indices). The graphs are built with DnaSPsoftware version 5.105 (LibradoetRozas, 2009). SSD and Rag indices aere obtained with Arlequin software version 3.5.1.3 (Excoffieret al., 2010).

\section{Results:-}

Nucleotides sequences alignment:-

An area of $C y t b$ and an area of $F G B$ were sequenced for normal and cancerous tissues among 30 patients suffering from breast cancer.

\section{Study of $\boldsymbol{C y t} \boldsymbol{b}$ and $\boldsymbol{F G B}$ genetic diversity:-}

$C y t b$ presents a most polymorphism compared to $F G B$. Transition percentages are more importants than that of tranversions among $C y t b(60 \%)$. Contrariwise, among $F G B$ percentages of transversions are higher than that of transitions $(58.9 \%$ ) (table 1$)$. The results revealed a predominance of A and T $(57.17 \%$ for $C y t b ; 62.6 \%$ for $F G B)$ with respect to $\mathrm{C}+\mathrm{G}(42.83 \%$ for $C y t b ; 37.4 \%$ for $F G B)$. Our results revealed a mutation bias in $\mathrm{C}$ and $\mathrm{G}$ to the third position of the codon. Cyt $b$ substitution evolve most rapidity in the third position of the codon with a molecular distance of $0.285+/-0.026$ compared to the molecular distances to the first $(0.161+/-0.015)$ and the codon second position (0.195+/-0.019). Genetic diversity indices analysis sho high values of $\mathrm{h}$ and $\pi$ for $C y t b$ and a strong $\mathrm{h}$ and a weak $\pi$ for $F G B$ (table 1 ).

Table 1:- $C y t$ band $F G B$ genetic parameters for cancerous tissues

\begin{tabular}{|c|c|c|}
\hline Settings & $C y t b$ & $F G B$ \\
\hline Sample size, $\mathrm{n}$ & 30 & 30 \\
\hline Number of sites, $\mathrm{N}$ & 325 & 623 \\
\hline Monomorphic sites & 108 & 612 \\
\hline Polymorphic sites & 217 & 11 \\
\hline Singleton variable sites & 76 & 8 \\
\hline Parsimony informative sites & 141 & 3 \\
\hline Total number of mutations, Eta & 315 & 13 \\
\hline Number of haplotypes, $\mathrm{h}$ & 30 & 10 \\
\hline Average number of nucleotide differences $(\mathrm{k})$ & 47,030 & 1,467 \\
\hline Nucleotide frequencies $(\%)$ & $\frac{\mathrm{ATCG}}{26.75} 30.42 \quad 12.13 \quad 30.70$ & $\frac{\mathrm{ATCG}}{31.41} 31.19 \quad 17.50 \quad 19.90$ \\
\hline $1^{\text {st }}$ position & $\begin{array}{llll}18 & 13.1 & 42.8 & 25.7\end{array}$ & \\
\hline $2^{\text {nd }}$ position & $\begin{array}{llll}30 & 18.3 & 19.9 & 32\end{array}$ & \\
\hline $3^{\text {rd }}$ position & $\begin{array}{llll}43 & 5.8 & 16.2 & 34.6\end{array}$ & \\
\hline $\begin{array}{l}\text { Molecular distances } 1^{\text {st }} \text { position } \\
0.161+/-0.015\end{array}$ & $\begin{array}{l}2^{\text {nd }} \text { position } 3^{\text {rd }} \text { position } \\
0.195+/-0.019 \quad 0.285+/-0.026\end{array}$ & \\
\hline Transitions & $60 \%$ & $41.06 \%$ \\
\hline Transversions & $40 \%$ & $58.9 \%$ \\
\hline $\mathrm{R}$ (Transition rate / Transversion rate) & 1.453 & 0.637 \\
\hline Haplotypesdiversity(h) & 1.000 & 0.800 \\
\hline Nucleotidediversity $(\pi)$ & 0.14471 & 0.00235 \\
\hline
\end{tabular}

Cyt $b$ Amino acids variability:-

We remark that the frequency of $C y t b$ amino acid is lightly difference between sane tissues and cancerous ones without any significant statistic (table 2). However, we observe a significant value on glutamine. 
Table 2:- $C y t b$ amino acids frequency

\begin{tabular}{|l|l|l|l|}
\hline Aminoacids & Normal tissues & Cancerous tissues & P- Value \\
\hline Ala & 7.46695 & 7.07778 & 0.936 \\
\hline Cys & 4.57306 & 5.08058 & 0.868 \\
\hline Asp & 5.25187 & 4.76524 & 0.870 \\
\hline Glu & 0 & 0.42046 & 0.038 \\
\hline Phe & 1.07181 & 1.40154 & 0.795 \\
\hline Gly & 10.11075 & 9.11002 & 0.810 \\
\hline His & 1.39335 & 2.06727 & 0.697 \\
\hline Ile & 8.71739 & 8.05886 & 0.858 \\
\hline Lys & 4.78742 & 5.95655 & 0.704 \\
\hline Leu & 7.89567 & 8.05886 & 0.958 \\
\hline Met & 10.46802 & 9.25017 & 0.775 \\
\hline Asn & 3.00107 & 2.97827 & 0.966 \\
\hline Pro & 5.14469 & 4.87035 & 0.922 \\
\hline Gln & 2.32225 & 2.10231 & 0.923 \\
\hline Arg & 1.89353 & 1.47161 & 0.821 \\
\hline Ser & 8.50303 & 8.51436 & 1 \\
\hline Thr & 5.71632 & 6.13174 & 0.904 \\
\hline Val & 6.64523 & 6.93763 & 0.932 \\
\hline Trp & 3.00107 & 3.43377 & 0.872 \\
\hline Tyr & 2.03644 & 2.31254 & 0.883 \\
\hline
\end{tabular}

\section{Genetic differentiation:-}

Genetic distances analysis between normal tissues and cancerous ones for each gene revealed an important genetic diversity for $C y t b(\mathrm{~d}=0.136)$, with respect to $F G B$ that has no mutation $(\mathrm{d}=0.003)$. Results are consigned in table III. For $C y t b$, the value of genetic distance inside cancerous tissues is superior to that of sane tissues $(\mathrm{d}=0.093)$. Contrariwise, no difference is noticed inside sane tissues for $F G B(\mathrm{~d}=0.006)$ and inside cancerous tissues $(\mathrm{d}=$ 0.000).

Table 3:-intra and inter-group genetic distance

\begin{tabular}{|l|l|l|l|}
\hline Genesamplified & Groupes & $\begin{array}{l}\text { Genetic distances } \\
\text { Intra-groupe }\end{array}$ & $\begin{array}{l}\text { Genetic distances } \\
\text { inter-groupe }\end{array}$ \\
\hline \multirow{2}{*}{ Cyt $b$} & Normal tissues & 0.093 & \multirow{2}{*}{0.136} \\
\cline { 2 - 4 } & Cancerous tissues & 0.112 & 0.003 \\
\cline { 2 - 3 } & Normal tissues & 0.006 & \\
\cline { 2 - 3 } & Cancerous tissues & 0.000 & \\
\hline
\end{tabular}

\section{Section signature tests:-}

Under a neutrality hypothesis $(\mathrm{dN}=\mathrm{dS})$ the probability value is -3.16 with a value of $\mathrm{p}(0.002)$ which is $<0.05$. From this result, the starting hypothesis is accepted. So, substitutions at the level of $C y t b$ follow the Kimura neutral model evolution. For the whole $C y t b$ codons, ATA (AUA) triplet that cods for methionine is positively sub selected $(\mathrm{dS}=1.618 ; \mathrm{dN}=8.561, \mathrm{dN}-\mathrm{dS}=6.943$ with a value p. $=0.048)$. As for $F G B$, the respective values Fs of Fu $(-$ $6.917 ; \mathrm{P}=0)$ and of R2 $(0.162 ; \mathrm{P}=0)$ of Ramos are significantly negativeand positive. However, Tajima D ($0.56656 ; \mathrm{P}>0.3$ ) is not significantly negative (table 4 ).

Table 4:-signature selection tests value

\begin{tabular}{|l|l|l|}
\hline & $C y t b$ & P-value \\
\hline dN/dS & -3.162 & 0.002 \\
\hline & $F G B$ & P-value \\
\hline D de Tajima & -0.56656 & 0.30600 \\
\hline Fs of Fu & -6.91799 & 0.00000 \\
\hline R2 & 0.16261 & 0.0000 \\
\hline
\end{tabular}




\section{Distribution disparity analysis (Mismatch distribution):-}

Distribution disparity of base pairs for both genes shows the expected and observed frequencies (full of dotted lines respectively) differences by pairs between samples. Results testify multimodal distributions for both genes (figure $1)$.
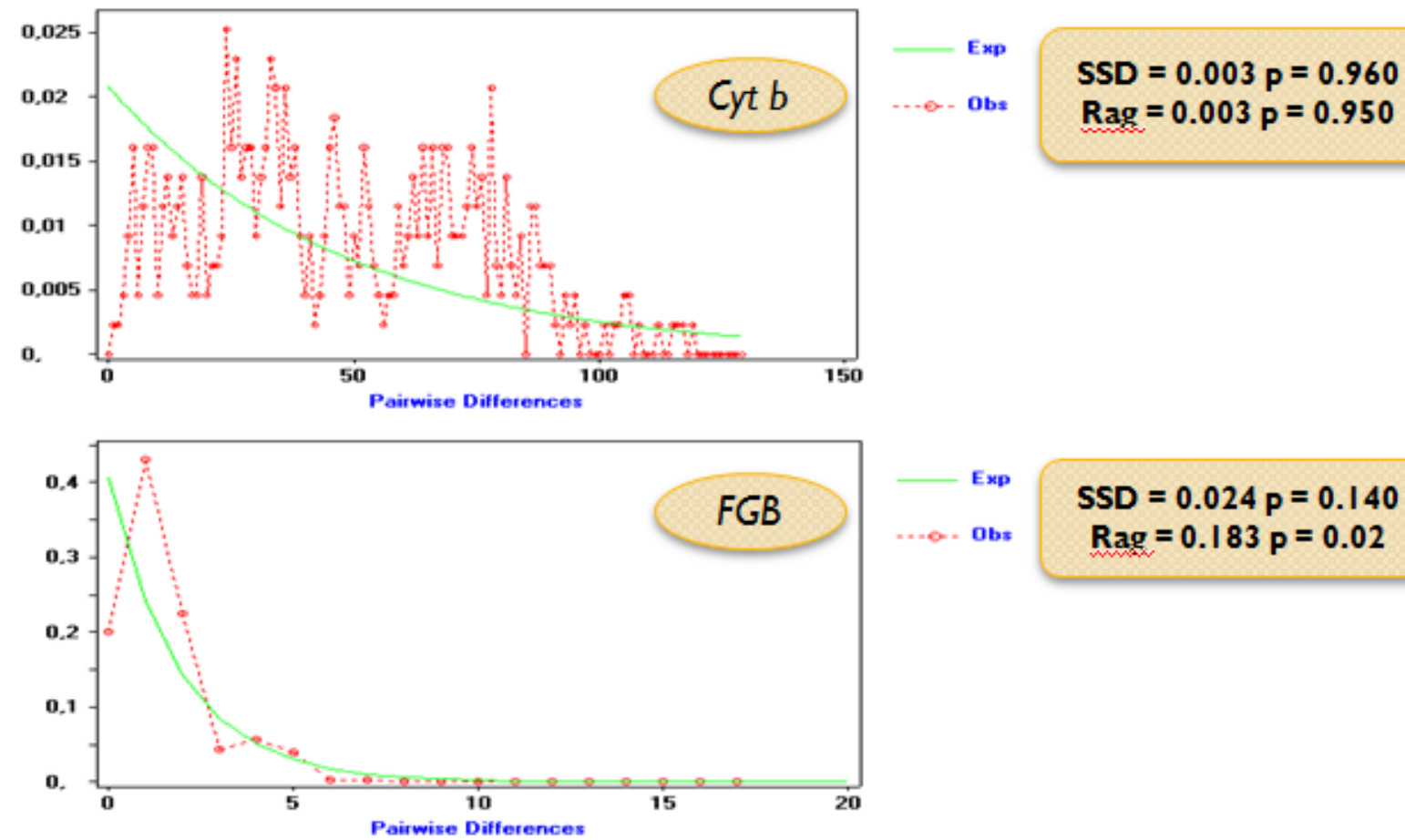

SSD $=0.024 p=0.140$

$\operatorname{Rag}=0.183 p=0.02$

Figure 3:- $C y t b$ and $F G B$ mismatch distribution curb

$C y t b$ SSD values (0.00336); $\mathrm{p}>0.9), F G B(0.02400 ; \mathrm{p}>0.1)$, are positive and no significant for both gene (pictures V). Contrariwise, Rag values, Cyt $b(0.00368 ; \mathrm{p}>0.9, F G B(0.18309)$, are positive and significant in $F G B$ whereas they are negatives and no significant for $C y t b$ (table 5).

Table 5:-Values of SSD, Rag and their P-values

\begin{tabular}{|l|l|l|}
\hline & $C y t b$ & $F G B$ \\
\hline SSD & 0,00336 & 0,02400 \\
\hline P-value & 0,96000 & 0,14000 \\
\hline Rag & 0,00368 & 0,18309 \\
\hline P-value & 0,95000 & 0,02000 \\
\hline
\end{tabular}

\section{Discussion:-}

In this study, $C y t b$ which is a mitochondrial gene and $F G B$ which is a nuclear gene were analyzed among 30 Senegalese patients suffering from cancer breast. We proceeded to the study of genetic variability, of genetic differentiation and genetic evolution in order to compare cancerous tissues sequences of $C y t b$ and $F G B$ for the purpose of determining the implication of both genes in the mammary carcinogenesis.

Our results revealed a strong variability of $C y t b$ compared to $F G B$. This strong variability of $C y t b$ is in mutual agreement with the works by Mbayeet al., (2014). Several types of explanations can be considered.

It can be mentioned: a sparsely regular replication (Kunkel \& Loeb, 1981), mitochondrial polymerase would be less regular than that of the core, a deficiency or an absence of systems of correction and reparation and apparent absence of recombination as well as a rate of renewal and so, of more important replication than that of nuclear DNA (Brown et al., 1982). 
$C y t b$ number of variability (217) and $F G B(11)$ as well as that the substitutions of R, $C y t b$ (1.453), FGB (0.637) lead to nucleotide variability rate of DNAmt. That rate of substitutions was noticed by (Tan et al., 2002) while examining the presence of DNAmt mutation in breast cancer, of which $58 \%$ were the substitutions of gene $C y t b$ and the no coding area (D-Loop).Among mammal it was accurately estimated, that rate is higher than that described for only nuclear sequence and of a multiplicative factor of 5 or 10 (Brown et al.,1982). That rate is variable following genome area considered but remains globally higher.

DNAmt general characteristics of mutations are transitions C-T and A-G (Beckman \& Ames, 1997) that are in correlation with our results with $60 \%$ of substitutions that are transitions among $C y t b$. They declared that the main reason of DNAmt mutations in tumour is the high level of ROS. On contrast, among FGBtransversions types mutations (58.9\%) are high with respect to that of transitions $(41.06 \%)$. These transversiontypes substitutions wouldn't have not effect since they happened in an intronic area of $F G B$.

Our results reveal that each amino acid frequency deriving from cytochrome $b$ sequences are weakly differentiated between sane tissues and cancerous ones without a statistic signification except glutamine. Most of cancers like breast cancer depend on a high rate of aerobic glycolysis for their growth and survival. Paradoxically, some cells lineages of cancer present also the dependence to glutamine in spite of the fact that glutamine is a no essential amino acid that can be synthesized from glucose. The high absorption rate of glutamine by exposed cells depending on glutamine seemed not coming only from its role as nitrogen donor in nucleotides and amino acids of biosynthesis. Instead of that, glutamine plays a role in the required absorption of amino acid essential in the maintaining and the activation of the TOR kinase. Furthermore, in many cancerous cells, glutamine is the primary mitochondrial substrate as well as the support to maintain the potential of the mitochondrial membrane and integrity as well as the support of NADPH production necessary for oxydoreduction control and macromolecular synthesis (Levine etPuzio-Kuter, 2010).

In this present work, we have made a comparative study of genetic distance intra and inter sane and cancerous tissues of both genes. As for $C y t b$, inside cancerous tissues the value of genetic distance $(\mathrm{d}=0.112)$ is higher than that of sane tissues $(d=0.093)$. This can be explained by the fact that, cancerous cells are no longer under the control of cellular division regular mechanisms. One of the characteristics of cancer is the rapid proliferation of abnormal cells (OMS, 2012). And as for $F G B$, values don't nearly present a difference inside sane tissues (0.006) and inside cancerous tissues (0.000). Thisis explained by the aspect of nuclear DNA gene which has a less important replication than that of DNA mt (Brown et al., 1982). On contrat, the weak distance of $F G B(0.003)$, confirms the characteristic of nuclear DNA which has a mutation rate less important than that of DNAmt. Methionine is under positive selection for $C y t b$ gene $(\mathrm{dS}=1.618 ; \mathrm{dN}=8.561 . \mathrm{dN}-\mathrm{dS}=6.943$ with a value of $\mathrm{p}=0.048)$. In other words, it is advantageous to tumour evolution. Contrary to sane cells, most of tumour cells need a exogenous contribution of Methionine, an essential amino acid (Durandoet al., 2008). Molecular mechanisms that help explain their dependence to Methionine are numerous. In vivo, various approaches were realized in order to lack in Methionine. As the main source of Methionine is food, synthetic diet plan lacked in Met have been widely used. Other alternatives were to use metabolism inhibitors of Methionine or anenzymaticdegradation thanks to Methioninase. Among animal, deficiency in Methionine permit to limit tumour growth and reduce the height of some tumours. However, some studies also showed a limited effect over time with an upturn of the tumour growth after the interruption of the deficiency. These different modifications suggested the use of a deficiency in Methionine in tumour cells in association with conventional chemotherapy. Many pre-clinical studies showed a synergic effect of a deficiency association in Met and various cytotoxic agents. Currently, little clinical investigations were realized in order to explore this therapeutic strategy.

The observed number of differences between haplotypes doubly taken produced a multimodal distribution. The amount of variances squared SSD, Cyt $b(0.00336 ; \mathrm{p}>0.9), F G B(0.02400 ; \mathrm{p}>0.1)$ are positive and aren't significant for both gene. As for FGB, respective values: Fs of Fu $(-6.917 ; \mathrm{P}=0)$ and R2 (0.162; P = 0) of Ramos are significantly negative and positive. However, Tajima $\mathrm{D}(-0.56656 ; \mathrm{P}=>0.3)$ is not significantly negative. These positive and negative values of neutrality tests are due to bare mutations. These results suggest a constant height of cancerous cells population for both genes, as show multimodal distribution (Ramos-OnsisnsetRozas, 2002).

\section{Conclusion:-}

$C y t b$ implication in cancers, in particular in breast malignant tumour, is no more demonstrated and is more and more studied. However, $F G B$ is less implicated in breast malignant tumour than $C y t b$. As the role of mitochondria 
is known in the apoptosis, the presence of these mutations could contribute to alter cellular response to anticancerous agents.

A significant difference of glutamine frequency between normal tissues and cancerous tissues was obtained. These results from Senegalese women suffering from breast cancer should be confirmed in quantifying the level of twenty amino acids from serum or plasma of these patients unpaired to subject of control. Cancerous cells need glucoses for their development and glutamine is a no essential amino acid that can be synthesised from glucose. As glucose comes from carbohydrates, to eliminate carbohydrates, replaced by proteins and sane greases, would be less ananticancerous treatment without medicines. Methionine is necessary in carcinogenic processes. So, their inhibition is a means of reducing the growth of cancerous tumour.

\section{References:-}

1. Axelrod D., Smith J., Kornreich D., Grinstead E., Singh B., Cangiarella J. et Guth AA. (2008). Breast Cancer in Young Women. Journal of the American College of Sureons. 206 (6): 1193-1203.

2. Beckman KB. et Ames BN., (1997). Oxydatifdécomposition de l'ADN. The Journal of Biological Chemistry. 272: 1963319636.

3. Bertram J. S. (2001). «The molecular biology of cancer». Molecular Aspects of Medicine. 21 (6):167-223.

4. Blakely E.M., Mitchell A.L., Fisher N., Meunier B., Nijtmans L.G., Schaefer A.M., Jackson M.J., Turnbull D.M. et Fayler R.W. (2005). A mitochondrial cytochrome b mutation causing severe respiratory chain enzyme deficiency in human and yeast. Federation of EuropeanBiochemicalSocieties. 272 (14): 3583-3592.

5. Blankenship \& Robert. 2009. Molecular Mechanisms of photosynthesis. Blackwell Publishing. 43 (2): 124-132.

6. Brown W.M., Prager E.M., Wang A. et Wilson A.C., (1982). Mitochondrial DNA sequences of Primates: tempo and mode of evolution. Journal of molecular evolution.18 : 225-239.

7. CIRC; Le cancer dans le monde. Rapport, IARC Press, (2013), 354 pages. Consultable à l'URL : http : www.iarc.fr/fr/publications/pdfs-online/wcr/2003/Le cancer dans le monde pdf.

8. Claus E.B. etRisch N. (1991). Genetic analysis of breast cancer in the cancer and steroid hormone study.The American Journal of Human Genetics.48 (2): 232-242.

9. Dem A., Traoré B., Dieng M.M., Diop P.S., Lalami M.T., Diop M., Dangou J.M. et Touré P. (2008). Les cancers gynécologiquesetmammaires à l'institut du cancer de Dakar. Cahiers d'études et de recherché francophones/ Santé, 18 (1): 25-29

10. Dumitrescu R.G. etCotarla I. (2005). Understanding breast cancer risk -- where dowe stand in 2005? Journal of Cellular and MolecularMedicine. 9:208-221.

11. Durando X., Thivat E., Gimbergues P., Cellarier E., Abrial C, Dib M, Tacca O. et Chollet P. (2008). Dépendance en Méthionine des cellules cancéreuses :une nouvelle approchethérapeutique. Bulletin du cancer. 15 (1) : 69-77.

12. ExcoffierL. etLisher H.E.L. (2010). Arlequinsuite version 3.5: A new series of perform population genetics analyses under linux and windows. Molecular, EcologyResources, 10 : 564-567.

13. Hall J., et Angele S. (1999). Radiation, DNA damage and cancer. MolecularMedecinToday. 5 :157-164. Kunkel T.A. et Loeb L.A. (1981). Fidelity of mammalian DNA polymerases.Science.213 : 765-767.

14. Librado P et J Rozas (2009)."DnaSP v5: A software for comprehensive analysis of DNA polymorphism data." Bioinformatics 25: 1451-1452.

15. Levine A.J. etPuzio-Kuter A.M. (2010). The control of the metabolic switch in cancers by oncogenes and tumor suppressor genes. Science. $330: 1340-1344$.

16. Mbaye. F., Dem A., Fall M., Mbaye E.S., Diop G. R., Ndiaye M.S., NiangA. D. etSembène M. (2014). Correlation of clinical and pathological parameters with the diversity and genetic evolution of breast cancer in Senegalese women. British Journal of Medecine and Medical Sciences. 4 (14): 2627-2638.

Nei M. (1978) E Stimation of average heterozygosity and genetic distance from a small number of individuals.Genetics, 89: 853-590.

17. OMS ; communiqué de presse $\mathrm{n}^{\circ} 223,12$ décembre2013. Consultable à l'URL: www.iarc.fr/fr/mediacentre/pr/2013/pdfs/pr223_F.pdf

18. OMS. (2012).Cancer. Accès. Consultable à l'URL : http://www.who.int/topics/cancer/fr/

19. Ramos-Onsins S.E. et Rozas J. (2002). "Statistical properties of new neutrality tests against population growth." Molecular Biology and Evolution. 19: 2092-2100.

20. Tajima F., 1989. Statistical method for testing the neutral mutation hypothesis by DNA polymorphism. Genetics $123,585-$ 595.

21. Tamura K, Stecher G, Peterson D, Filipski A et Kumar S (2013) MEGA6: Molecular Evolutionary Genetics Analysis Version 6.0.MolecularBiology and Evolution 30: 2725-2729.

22. Tan D.J., Bai R.K. et Wong. LJ. (2002). Cancer Research. 62: 972-976. Voet D. etVoet J. G. 2002.Biochimie.Trad.deJ'anglais par Y. Gaudemer. Paris: De BoeckUniversité, 1361 p.

23. Wilkie D., Evans I.H., Egilsson V., Diala E.S. et Collier D. (1983). Mitochondria, cell surface, and carcinogenesis. International review of cytology. Supplement; 15: 157-189. 